\title{
Impairment of tritan colour vision after initiation of treatment with zidovudine in patients with HIV disease or AIDS
}

\author{
Stephan A Geier, Manfred Held, Johannes R Bogner, Ursula Kronawitter, Thomas Berninger, \\ Volker Klauss, Frank D Goebel
}

Zidovudine (3'-azido-2', $3^{\prime}$ - dideoxythymidine) is a drug with proved antihuman immunodeficiency virus (HIV) reverse transcriptase activity. It has been clearly demonstrated that the benefits of zidovudine outweigh the risks of its use. ${ }^{1-5}$ Different adverse effects have been reported for zidovudine, including anaemia, neutropenia, nausea, vomiting, myalgias, abnormalities of liver function, bluish nail pigmentation, headaches, myositis, and trichiasis. ${ }^{67}$ Colour vision deficits have been reported for patients with AIDS or HIV disease, ${ }^{89}$ and it has been shown that this defect is most prominent for tritan vision.' The pathogenesis of colour vision deficits in patients with HIV disease remains unclear. We wish to report the occurrence of a temporary decrease in tritan colour contrast sensitivity in two patients with HIV disease starting or restarting treatment with zidovudine.

\section{Case reports}

CASE 1

A 31-year-old patient was referred to the university eye hospital for routine examination after diagnosis of HIV infection and lymphadenopathy syndrome. The patient had attended the medical outpatient clinic because of a 1 month history of fever accompanied by swelling of lymph nodes. He tested HIV positive for the first time during this diagnostic examination which was 2 weeks before the first ophthalmic examination. Visual acuity was $20 / 20$ in both eyes with correction. Biomicroscopic examination revealed normal findings except for a discrete sludging of the blood column in the conjunctival vessels. On indirect ophthalmoscopy five cotton wool spots were seen in the right eye, and one in the left eye. Colour contrast sensitivity was tested using a high sensitivity computer graphics system developed by Arden et $a l .{ }^{10}$ The thresholds for the three colour axes were within normal limits: tritan right eye (RE) $4 \cdot 7$, and left eye (LE) $4 \cdot 2$; deutan RE $3 \cdot 3$, and LE 3.2; protan RE 3.0, and LE 3.1. The age corrected normal values are (mean (2 SE)): tritan $3.9(2 \cdot 2)$; deutan $4 \cdot 3(2 \cdot 2)$; and protan $4.0(1 \cdot 9)$. The absolute CD4+ lymphocyte count was $219 \times 10^{6} / 1$, and treatment with zidovudine (500 mg per day) was started. This was the only drug administered to the patient. Seven days after initiation of treatment with zidovudine the patient attended hospital with a 3 day experience of slightly blurred vision in both eyes. Ophthalmic examination, and deutan and protan colour vision were unchanged, but tritan vision was impaired: tritan RE 7•4, and LE 7·5. Zidovudine treatment was continued. One week later the subjective symptoms disappeared. Tritan thresholds were RE 5.4, and LE 4.6. On subsequent follow ups tritan vision improved to baseline levels, and was in a range between 3.7 and 4.3 in both eyes.

\section{CASE 2}

The second patient was a 26-year-old woman with a 9 month history of AIDS after one episode of Pneumocystis carinii pneumonia. She was referred to the university eye hospital for ophthalmic examination because of diplopia. Treatment with zidovudine had been discontinued 2 months earlier because of neutropenia, but the patient was still on Pneumocystis carinii prophylaxis with trimethoprim and sulphamethoxazole. The absolute CD4+ lymphocyte count was $70 \times 10^{6} / 1$. Visual acuity was $20 / 20$ in both eyes with correction. Ophthalmic examination revealed a sixth nerve palsy of the right eye. Otherwise ophthalmic examination was normal and colour contrast sensitivity thresholds were within normal limits: tritan RE 3.8, and LE 3.9; deutan RE 3.6, and LE 3.6; protan RE 3.7, and LE 3.7.

Cranial magnetic resonance imaging showed a lesion in the area of the right pons and a second lesion in the left anterior part of the corpus callosum, both with surrounding oedema. Clear ring-like enhancement was seen after application of Gd-DTPA. The location of the lesion in the pons was in accordance with compressive damage to the intracerebral path of the sixth nerve. The diagnosis of cerebral toxoplasmosis was assumed, and treatment with pyrimethamine ( $50 \mathrm{mg}$ per day), clindamycin ( $2400 \mathrm{mg}$ per day), and folinic acid (15 mg per day) was started. Ten days later diplopia disappeared. Treatment with zidovudine ( $500 \mathrm{mg}$ per day) was re-established 2 months later. Tritan colour contrast sensitivity increased to RE 6.4, and LE 
6.5 measured 3 days after the reinitiation of treatment with zidovudine, but otherwise ophthalmic findings were normal, especially the values for deutan and protan vision. Two weeks later tritan colour contrast sensitivity was RE $3 \cdot 5$, and LE 3.8 and other findings were unchanged.

\section{Comment}

Alterations of colour vision have been reported for numerous drugs. ${ }^{112}$ Acquired alterations of tritan vision are usually related to retinal damage. ${ }^{13}$ Therefore, the dyschromatopsia in the two reported cases is expected to be related to retinal damage.

Recently, retinal damage has been reported for children treated with $2^{\prime}, 3^{\prime}$ - dideoxyinosine. ${ }^{14}$ The authors used electrophysiological methods to measure retinal function, but no tests for colour vision were performed. They suggest that $2^{\prime}, 3^{\prime}$-dideoxyinosine, which is also a dideoxynucleoside like zidovudine, causes a diffuse dysfunction of the retinal pigment epithelium.

The pathogenesis of colour vision deficits in patients with symptomatic HIV infection or AIDS remains unclear. It was proposed that the HIV-related retinal microangiopathic syndrome plays an important role in the pathogenesis of those colour vision deficits. Our observations suggest that a temporary shift in tritan colour vision is an adverse effect at the beginning of treatment with zidovudine. This shift in tritan vision might be due to a temporary interference of zidovudine with the production of visual pigment, or a temporary alteration of the pigment epithelium. Nevertheless, other factors may underly the changes. It cannot be ruled out that long term application of zidovudine might contribute to the development of colour vision deficits described for patients with HIV disease. Health care professionals involved in the treatment of patients with HIV disease should be aware of any abnormal drug or disease related effects.

This study was supported by Bundesministerium für Forschung und Technologie, and by Bundesministerium für Gesundheit, Germany, grant FKZ BGA III-002-89/FVP.

We wish to thank Mrs Ch Hörmann and Mrs cand med $\mathrm{H}$ Schmidt-Kittler for their help.

1 Corey L, Fleming TR. Treatment of HIV infection - progress in perspective. $N$ Engl f Med 1992; 326: 484-6.

2 Fischl MA, Richmann DD, Hansen N, Collier AC, Carey JT, Para MF, et al. The safety and efficacy of zidovudine (AZT) in the treatment of subjects with mildly symptomatic human in the treatment of subjects with mildy symptomatic human blind, placebo controlled trial. Ann Intern Med 1990; 112: 727-37.

3 Volberding PA, Lagakos SW, Koch MA, Pettinelli C, Myers MW, Booth DK, et al. Zidovudine in asymptomatic human immunodeficiency virus infection: a controlled trial in persons with fewer than 500 CD4-positive cells per cubic millimeter. $N$ Engl f Med 1990; 322: 941-9.

4 Hamilton JD, Hartigan PM, Simberkoff MS, Day PL, Diamond GR, Dickinson GM, et al. A controlled trial of early versus late treatment with zidovudine in symptomatic human immunodeficiency virus infection. $N$ Engl $f$ Med 1992; 326: 437-43.

5 Graham NMH, Zeger L, Park LP, Vermund SH, Detels R, Rinaldo CR, et al. The effects on survival of early treatment of human immunodeficiency virus infection. $N$ Engl $千$ Med 1992; 326: 1037-42.

6 Klutman NE, Hinthorn DR. Excessive growth of eyelashes in a patient with AIDS being treated with zidovudine [Letter]. a patient with AIDS being treated

7 Yarchoan R, Mitsuya H, Myers CE, Broder S. Clinical pharmacology of $3^{\prime}$-azido-2', $3^{\prime}$-dideoxythymidine (zidovudine) and related dideoxynucleosides. $N$ Engl f Med 1989; 321: 726-38.

8 Quiceno JI, Capparelli E, Sadun AA, Munguia D, Grant I, Listhaus $\mathrm{A}$, et al. Visual dysfunction without retinitis in patients with acquired immune deficiency syndrome. $A m \mathcal{F}$ Ophthalmol 1992;113: 8-13.

9 Geier SA, Berninger T, Kronawitter U, Bogner JR, Klauss V, Goebel F-D. Colour vision in AIDS patients and HIV positives. VIIth International Conference on AIDS, Florence, 16-21 June 1991. Abstractbook, Abstract MB 2417, 1991: 286.

10 Arden GB, Gündiz K, Perry S. Colour vision testing with a computer graphics system. Clin Vis Sci 1988; 2: 303-20.

11 Lyle WM. Drugs and conditions which may affect colour vision. Part I: Drugs and chemicals. F Am Optometric Ass 1974; 45: 47

12 Zrenner E. Neurophysiological aspects of colour vision in primates. In: Studies of brain function. Vol 9. New YorkHeidelberg: Springer, 1973.

13 Hart WM. Acquired dyschromatopsias. Surv Ophthalmol 1987; 32: 10-31

14 Whitcup SM, Butler KM, Caruso R, de Smet MD, Rubin B Husson RN, et al. Retinal toxicity in human immunodeficiency virus-infected children treated with 2',3'dideoxyinosine. Am $\mathcal{F}$ Ophthalmol 1992; 113: 1-7.

\title{
Bilateral retinal haemorrhages following epidural injection
}

\author{
C Ling, P L Atkinson, C G F Munton
}

Kent County Ophthalmic and Aural Hospital, Church Street, Maidstone, Kent ME14 1DT C Ling P L Atkinson C G F Munton Correspondence to: Mr P L Atkinson, King's College Hospital, Denmark Hill, London SE5 9RS. Accepted for publication 12 January 1993
Epidural analgesia is widely used in the management of chronic back pain and in a variety of obstetric and surgical procedures and complications are well described. ${ }^{1}$ We report a case of bilateral retinal haemorrhages following caudal epidural injection under general anaesthesia for the relief of chronic back pain.

\section{Case report}

A 47-year-old woman underwent a caudal epidural injection and sciatic stretch under general anaesthesia for the relief of chronic back pain following a road traffic accident. A spinal decompression had been performed 2 years previously. She was generally well with no history of diabetes mellitus or hypertension and no eye problems apart from moderate right amblyopia. General anaesthesia was induced with propofol and maintained with nitrous oxide in oxygen. A sciatic stretch was performed and an injection of $80 \mathrm{mg}$ depomedrone in $20 \mathrm{ml}$ 